Document downloaded from:

http://hdl.handle.net/10251/145993

This paper must be cited as:

Redtenbacher, C.; Kiesling, C.; Malin, M.; Wimmer, A.; Pastor, JV.; Pinotti, M. (03-2). Potential and Limitations of Dual Fuel Operation of High Speed Large Engines. Journal of Energy Resources Technology. 140(3):1-10. https://doi.org/10.1115/1.4038464

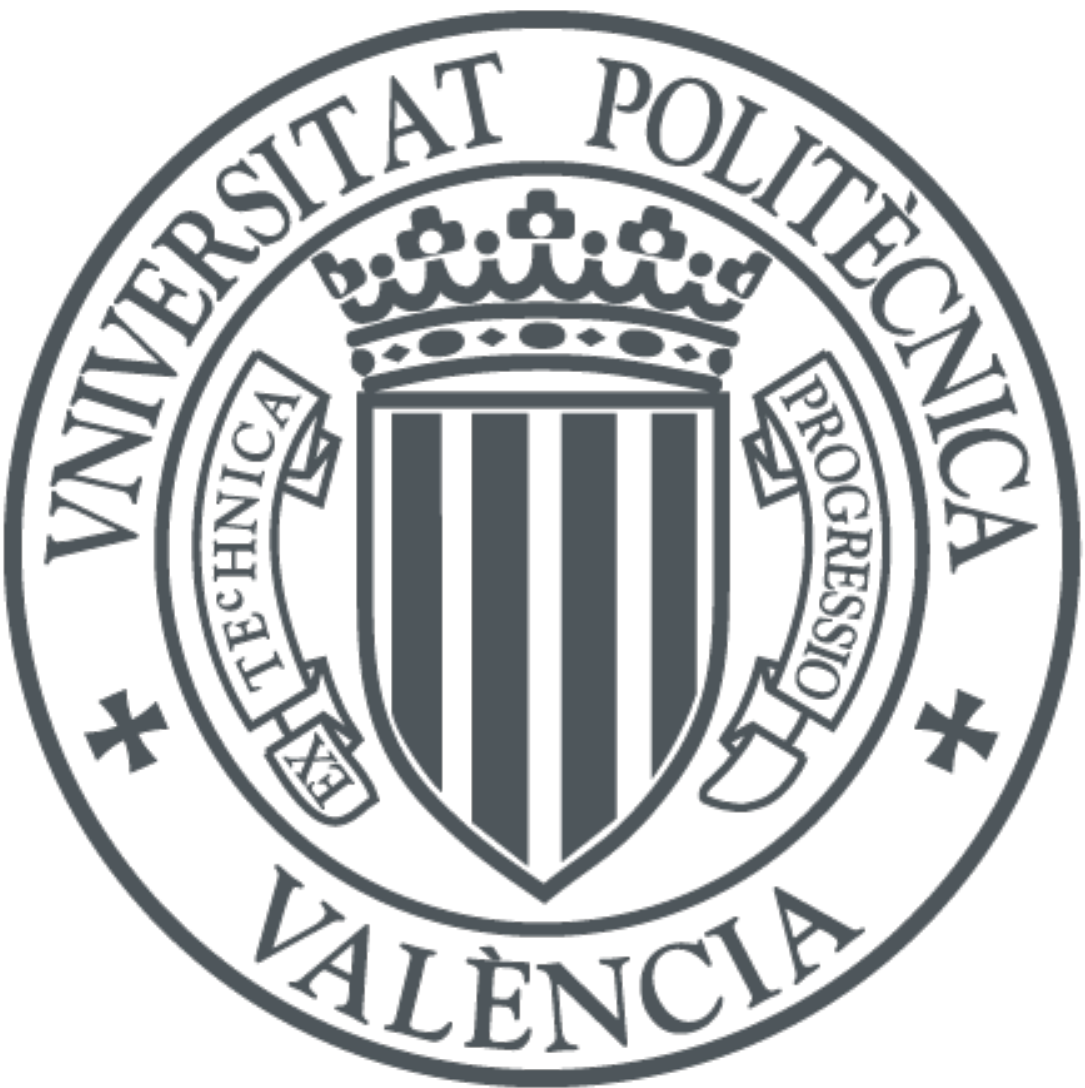

The final publication is available at https://doi.org/10.1115/1.4038464

Copyright ASME International

Additional Information 


\title{
Potential and Limitations of Dual Fuel Operation of High Speed Large Engines
}

\author{
Christoph Redtenbacher \\ LEC GmbH \\ Graz, Austria
}

Andreas Wimmer

LEC GmbH /

Graz University of Technology

Graz, Austria

\author{
Constantin Kiesling \\ LEC GmbH \\ Graz, Austria
}

\author{
Jose V. Pastor \\ CMT-Motores Térmicos, \\ Universitat Politècnica de \\ València \\ València, Spain
}

\author{
Maximilian Malin \\ LEC GmbH \\ Graz, Austria
}

\author{
Mattia Pinotti \\ CMT-Motores Térmicos, \\ Universitat Politècnica de \\ València \\ València, Spain
}

\begin{abstract}
The aim of this paper is to identify and investigate the potential and limitations of diesel-gas combustion concepts for high speed large engines operated in gas mode with very small amounts of pilot fuel ( $<5 \%$ diesel fraction). Experimental tests were carried out on a flexible single cylinder research engine (displacement $6.24 \mathrm{dm}^{3}$ ) equipped with a common rail system. Various engine configurations and operating parameters were varied and the effects on the combustion process were analyzed. The results presented in this paper include a comparison of the performance of the investigated dual fuel concept to those of a state-of-the-art monofuel gas engine and a state-of-the-art monofuel diesel engine. Evaluation reveals that certain limiting factors exist that prevent the dual fuel engine from performing as well as the superior gas engine. At the same $\mathrm{NO}_{\mathrm{x}}$ level of $1.3 \mathrm{~g} / \mathrm{kWh}$, the efficiency of the dual fuel engine is $3.5 \% \mathrm{pts}$. lower than that of the gas engine. This is caused by the weaker ignition performance of the injected pilot fuel compared to that of the gas scavenged prechamber of the gas engine. On the other hand, the dual fuel concept has the potential to compete with the diesel engine. The dual fuel engine can be operated at the efficiency level of the diesel engine yet with significantly lower $\mathrm{NO}_{x}$ emissions $(3.5 \mathrm{~g} / \mathrm{kWh}$ and $6.3 \mathrm{~g} / \mathrm{kWh}$, respectively). Since the injection of pilot fuel is of major importance for flame initialization, and thus for the main combustion event of the dual fuel engine, optical investigations in a spray box, measurements of injection rates, and three-dimensional (3D) computational fluid dynamics (CFD) simulation were conducted to obtain even more detailed insight into these processes. A study on the influence of the diesel fraction shows that diminishing the diesel fraction from $3 \%$ to lower values has a significant impact on engine performance because of the effects of such a reduction on injection, ignition delay, and initial flame formation. The presented results illustrate which operating strategy is beneficial for engine performance in terms of low $\mathrm{NO}_{x}$ emissions and high efficiency. Moreover, potential measures can be derived which allow for further optimization of the diesel-gas combustion process.
\end{abstract}

Keywords: high speed large engine, dual fuel, diesel-gas, diesel injection, spray box, 3D CFD 


\section{Introduction}

Interest is growing in using fully flexible diesel-gas dual fuel engines able to run in pure diesel mode as well as in dual fuel mode for power generation and propulsion on land and at sea. Dual fuel operation with these engines is characterized by the feeding of a premixed gas-air mixture into the engine and compression ignition of the cylinder charge via direct diesel injection into the combustion chamber, cf., Ref. [1]. Benefits such as the flexibility to adapt the type of fuel to the market, fail-safe operation, and lower nitrogen oxides $\left(\mathrm{NO}_{\mathrm{x}}\right)$ emissions than diesel engines are convincing arguments for engine operators, cf., Refs. [2-8]. However, diesel-gas engine concepts still suffer from lower efficiency and worse combustion stability than state-of-the-art monofuel diesel engines and spark ignited gas engines when operated in the corresponding fuel mode, cf., Ref. [9]. To meet stringent NO emission legislation, high diesel substitution rates are necessary. Investigations of a large dieselgas dual fuel engine concept [10] indicate that diesel fractions ${ }^{1}$ in the range of $<1 \%$ are required to reduce the $\mathrm{NO}_{\mathrm{x}}$ emission level below $\mathrm{g} / \mathrm{kWh}$ when the engine is operated at its nominal indicated mean effective pressure (IMEP) of 24bar and without exhaust gas recirculation (EGR). Achieving adequate combustion stability within this operating range is an issue.

First, this paper evaluates the performance of a state-of-the-art diesel-gas dual fuel concept, comparing it to those of a monofuel gas engine and a monofuel diesel engine by providing a detailed analysis of their combustion processes based on experimental investigations on a large high speed single cylinder engine (SCE) with a displacement of $6.24 \mathrm{dm}^{3}$. The conceptual differences between these engine types are discussed and the reasons for the disadvantages in efficiency of current dual fuel technology are explained. The aim is to show the potential and the limitations of the dual fuel engine when it is operated at its nominal IMEP of 24bar without EGR and with very small amounts of pilot fuel ( $<5 \%$ diesel fraction) so that low engine-out $\mathrm{NO}_{\mathrm{x}}$ emissions can be obtained. The investigations have been limited to an operating range which provides combustion stability within a window that allows the combustion concept to be applied to a multicylinder engine.

Note that it has already been shown that very low $\mathrm{NO}_{\mathrm{x}}$ emissions can also be achieved with larger diesel fractions, cf., Refs. [3,5,11-15]. However, it must be taken into account that these investigations used boundary conditions that differ significantly from those of the investigations in this paper. Most of these combustion concepts were investigated at considerably lower engine loads ranging from approximately 3 to 12 bar IMEP. Furthermore, comparatively large cyclic variations of the IMEP and thus an unfavorable combustion stability were tolerated under certain operating conditions. The investigations of Eichmeier et al. in Ref. [11] and Nieman et al. in Ref. [12] also include higher loads of 19bar and 23bar IMEP, respectively, but comparatively high EGR rates of $50 \%$ were employed for the investigated operating points. Moreover, the engine size in this paper differs significantly from the displacements in the previously mentioned references which range from 0.6 to $2.4 \mathrm{dm}^{3}$ per cylinder.

Second, this paper analyzes combustion effects in dual fuel operation with small diesel fractions as the basis for further improvements of the combustion concept. Reducing the diesel fraction below $5 \%$ has a considerable influence on engine performance because of the effects of such a reduction on injection, ignition delay, and initial flame formation. The results of the SCE investigations show that it becomes more and more challenging to ensure stable ignition and fast combustion of the air-fuel mixture. In addition, it can be seen at very small diesel fractions in particular that the well-known relationship between the injection timing and combustion phasing of conventional engine concepts is no longer valid.

Effects of variations in diesel fraction and injection timing have already been investigated in Refs. [3,5,11,1316]. For example, Eichmeier et al. [11] studied the influence of the injection timing on combustion phasing, efficiency, and emissions at a comparatively high IMEP of 19bar while employing an EGR rate of 55\%. Krishnan et al. [3] investigated a wide range of pilot fuel injection timings on a heavy duty SCE at a brake mean effective pressure of 12.2bar and without EGR. A similar study of the injection timing at an IMEP of 5.1bar has been presented by Raihan et al. [5]. Common to these three studies is a discussion of the effect that under certain conditions, advancing the injection timing results in a retarding of the combustion phasing. Krishnan et al. [16] examined the effects of varying the diesel fraction on a heavy duty SCE at an IMEP of 6.1bar. The results show that larger diesel fractions yield shorter ignition delays and greater magnitudes of the initial premixed combustion peak of the diesel fuel.

\footnotetext{
${ }^{1}$ The diesel fraction describes the energetic amount of diesel fuel related to the total fuel energy fed into the engine.
} 
The aim of this publication is to study the effects of varying injection timing and diesel fraction in detail by employing additional methods apart from the SCE investigations. These methods focus on the pilot fuel injection event since it is of major importance for flame initialization and thus for the main combustion process. Consequently, optical investigations in a spray box, measurements of injection rates, and three-dimensional (3D) computational fluid dynamics (CFD) simulation were conducted to obtain highly detailed information about the fundamental effects. In contrast to the previously mentioned references, this paper focuses on studying the effects at high load engine operation (IMEP 24 bar) without EGR.

The combination of knowledge acquired of the specific deficits of state-of-the-art dual fuel engines and detailed information of fuel injection effects at very small diesel fractions provides the basis for further optimization of the dual fuel combustion process.

Table 1 Single cylinder engine technical specifications

\begin{tabular}{lc}
\hline \hline Rated speed & $1500 \mathrm{rpm}$ \\
Bore & $190 \mathrm{~mm}$ \\
Stroke & $220 \mathrm{~mm}$ \\
Displacement & $6.24 \mathrm{dm}^{3}$ \\
Conrod length & $425 \mathrm{~mm}$ \\
Compression ratio & Adjustable by modifying the piston geometry \\
Valve timing & Adjustable by modifying the camshaft geometry \\
Number of inlet/ exhaust valves & $2 / 2$ \\
Swirl/tumble & $0 / 0$ \\
Charge air & Provided by external compressors with up to 10bar boost pressure \\
Gas fuel supply & External mixture formation via a venturi mixer \\
Diesel fuel supply & Common rail system with up to 2200bar pressure \\
Balance of inertia forces & Four balancing shafts to compensate for first and second-order inertia forces \\
\hline \hline
\end{tabular}

\section{Experimental Setup}

Single Cylinder Engine Testing. Engine testing was carried out on a high speed four-stroke single cylinder research engine at LEC GmbH in Graz. The highly flexible SCE can be rebuilt quite easily to allow the investigation of different engine configurations such as monofuel diesel engine concepts and monofuel gas engine concepts as well as dual fuel engine concepts. The test bed is equipped with the latest crank angle (CA) and timebased measurement technology for all relevant parameters. Furthermore, the engine is supplied with conditioned charge air, burning gas, cooling water, and lubricating oil to ensure reproducible testing conditions. The back pressure in the exhaust pipe is controlled by a flap to simulate the presence of a turbocharger. All measurements were taken without making use of EGR. The main engine data of the investigated concepts are presented in Table 1. Table 2 summarizes the measurement technology applied on the SCE.

Table 2 Single cylinder engine measurement technology

\begin{tabular}{lll}
\hline \hline Quantity & \multicolumn{1}{c}{ Instrument } & \multicolumn{1}{c}{ Accuracy } \\
\hline Gas mass flow & Emerson Micro Motion CMFS015 & $60.25 \%$ of metered value \\
Air mass flow & Emerson Micro Motion CMF100 & $60.35 \%$ of metered value
\end{tabular}




\begin{tabular}{lll} 
Diesel mass flow & AVL Fuel Exact, MF 150KG SF & $0.1 \%$ of metered valuep0.002kg/h \\
Charge temperature & Resistance temperature sensor PT100 (3) & According to class A \\
Charge pressure & Piezoresistive pressure sensor, 0-16bar & $0.2 \%$ full scale output (FSO) \\
Charge humidity & Vaisala HUMICAP humidity transducer & $2.5 \mathrm{~g} \mathrm{H}$ O/kg air at 45C \\
Exhaust gas temperature Thermocouple type K (3) & According to class 1 \\
Exhaust gas pressure & Piezoresistive pressure sensor 0-16bar & $0.2 \%$ full scale output (FSO) \\
Exhaust gas emissions & AVL AMA i60 emission bench & Dependent on each exhaust gas component \\
NO $_{x}$ & AVL CLD i60 HHD & $1 \%$ FSO \\
Cylinder pressure & AVL piezoelectric transducer QC34C with & Cyclic temperature drift: 60.3bar; Thermo \\
Crank angle & AVL Micro IFEM 4P3G amplifier & shock error: DIMEP 61\% \\
Crank angle resolved & AVL 365 CC crank angle encoder & Resolution: 0.1CA \\
data acquisition & AVL IndiSet 642 Advanced Plus Gigabit & Resolution: 14bit \\
\hline
\end{tabular}

Monofuel Gas Engine. An optimized spark ignited gas engine concept was taken as a reference for the evaluation of the dual fuel combustion process. The cylinder head was equipped with a centrally mounted gas scavenged prechamber including a spark plug. This setup enables highly effective ignition of a lean mixture in the main combustion chamber, cf., Ref. [20]. The compression ratio was 12.5:1, and therefore, 0.5 points higher than that of the dual fuel engine. Furthermore, the intake valve closing (IVC) was 20CA earlier than that of the dual fuel engine. With this monofuel gas engine setup, a previously existing representative operating point with an IMEP of 24bar was chosen for evaluation of the dual fuel operation. The boundary conditions of this operating point differ slightly from those of the dual fuel operating points. The intake charge temperature was 50C and the intake air humidity was $8 \mathrm{~g} / \mathrm{kg}$. In addition, the scavenging gradient of the monofuel gas engine was based on a two-stage turbocharging concept.

Monofuel Diesel Engine. A state-of-the-art diesel engine concept consisting of a standard diesel injector (same nominal nozzle flow rate as the dual fuel wide range injector) and a well-balanced nozzle/piston bowl geometry was used as the benchmark for diesel operation. The compression ratio of 17:1 was significantly higher than those of the dual fuel engine setup and the gas engine setup. With the gas fueled engines, such a high compression ratio is not feasible as knocking combustion would occur. The diesel engine configuration has a 5CA earlier IVC than the dual fuel setup. Similar to the monofuel gas engine, a previously existing and representative operating point with an IMEP of 24bar was used for the comparison with dual fuel operation. While the intake temperature was the same, the intake air humidity was $3.9 \mathrm{~g} / \mathrm{kg}$ and thus lower than that of the dual fuel engine. The scavenging gradient of the diesel engine operating point was based on a single-stage turbocharging concept.

Spray Box and Rate of Injection Measurements. These investigations were carried out at the Universitat Politècnica de València, CMT-Motores Térmicos. A high temperature and high pressure spray box in which the thermodynamic conditions in an engine at the time of injection can be simulated up to a maximum temperature of $1000 \mathrm{~K}$ and a maximum pressure of 150bar was used to measure the liquid spray phase (Mie scattering technique) and the vapor spray phase (Schlieren technique) under inert conditions in a nitrogen atmosphere. A detailed description of the measurement techniques and the corresponding optical setups is given in Ref. [10]. Rate of injection (ROI) measurements were carried out with a commercial injection analyzer from the company IAV using the Bosch method [21], where the injector introduces diesel into a measuring tube filled with fuel. The discharge of fuel produces a pressure increase inside the tube proportional to the increase in fuel mass. The rate of this pressure increase corresponds to the injection rate. 
Table 3

Boundary conditions of dual fuel investigations

\begin{tabular}{ll}
\hline \hline Compression ratio & $12: 1$ \\
Nominal valve timing & Miller valve timing (cf., Refs. [17-19]) with early inlet valve closing BDC \\
IMEP & 24bar \\
Global excess air ratio & Varied from 1.6 to 1.8 \\
Intake charge temperature & $45 \mathrm{C}$ \\
Intake air humidity & $10.7 \mathrm{~g} / \mathrm{kg}$ \\
Intake charge pressure & Dependent on EAR \\
Gas supply pressure & Intake charge pressure p0.5bar \\
Gas quality & Natural gas \\
Gas composition for all tests & $\mathrm{CH}_{4}: 93.8 / 1.3$ vol \%, $\mathrm{C}_{2} \mathrm{H}_{6}: 3.3 / 0.2$ vol \%, \\
(average/standard deviation) & $\mathrm{C}_{3} \mathrm{H}_{8}: 1.3 / 0.6$ vol \%, $\mathrm{N}_{2}: 0.9 / 0.2$ vol \%, \\
& Other: 0.8 vol \% \\
Gas methane number for & $82.6 / 3.2$ \\
all tests & \\
(average/standard deviation) & \\
Diesel rail pressure & Varied from 700 to 2200bar \\
Diesel injection timing & Varied from 11 to 38CA before top dead center \\
Diesel quality & European standard diesel according to \\
Scavenging gradient & ONORM EN 590 with a cetane number€ 51 \\
\end{tabular}

a The global excess air ratio considers both gaseous fuel and diesel fuel.

\section{Potential Assessment of Diesel-Gas Dual Fuel Engines}

The results of the SCE investigations of the dual fuel concept and the monofuel concepts provide insight into the effects that cause the disadvantages in efficiency of current dual fuel technology. Figure 1 shows the indicated high pressure efficiency ${ }^{2}\left(g_{\_ \text {_HP }}\right)$ of a variety of dual fuel operating points plotted against the combustion phasing represented by MFB50\% (50\% mass fraction burned). It is possible to distinguish between operating points at $5 \%$ diesel fraction measured with the wide range injector and operating points at $0.5-1 \%$ diesel fraction measured with the pilot injector. The shading of the points represents the excess air ratio (EAR). The points at low diesel fractions were all operated at an EAR of 1.7, which turned out to be an optimum value for this range of diesel fractions. To achieve different combustion phasings, the start of injection was varied within the range of 11 to 38CA before top dead center (TDC). Rail pressures ranged from 700 to 2200 bar.

In addition, the reference points of the monofuel gas configuration and the monofuel diesel configuration are shown in the graph.

\footnotetext{
${ }^{2}$ The indicated high pressure efficiency is based on the indicated power of the high pressure phase of the engine working cycle calculated from bottom dead center (BDC) to BDC. The comparison of this efficiency helps avoid falsification of the results caused by differences between the engine configurations during the gas exchange phase.
} 

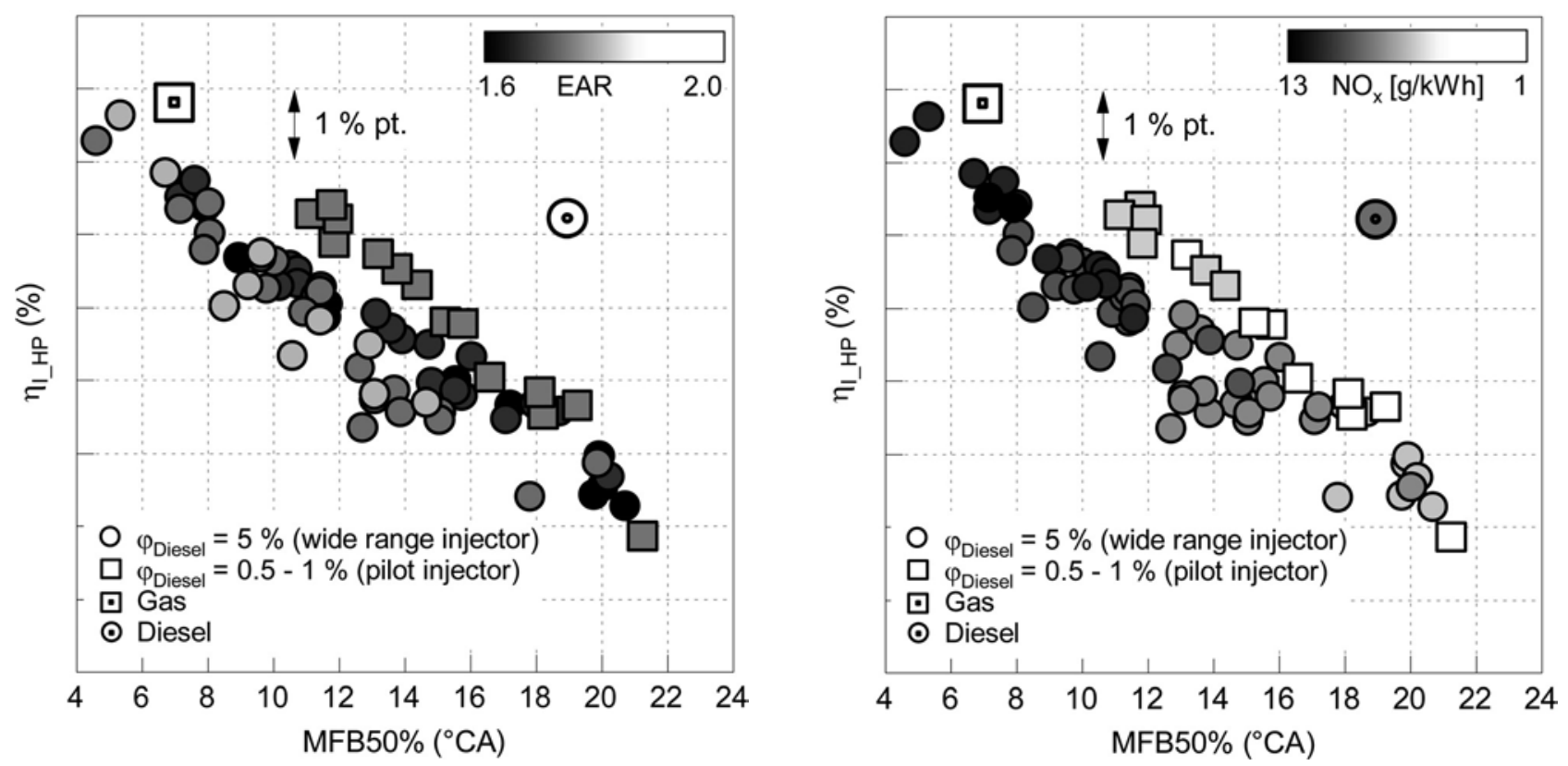

Fig. 1 Comparison of engine concepts-the impact of excess air ratio and combustion phasing on efficiency

Fig. 2Comparison of engine concepts $-\mathrm{NO}_{\mathrm{x}}$ trends

The engine parameter settings can be seen as beneficial in terms of efficiency while meeting the $\mathrm{NO}_{\mathrm{x}}$ emission limits of $500 \mathrm{mg} / \mathrm{m}^{3}$ (norm) at $5 \% \mathrm{O}_{2}(1.3 \mathrm{~g} / \mathrm{kWh})$ for gas operation (corresponding to Germany's TA-Luft emission legislation for spark ignited gas engines and dual fuel engines with pilot injection [22]) and 6.4g/kWh for diesel operation (corresponding to U.S. Environmental Protection Agency Tier 2 emission legislation for $\mathrm{NO}_{\mathrm{x}}$ pnonmethane hydrocarbons, which is valid for nonroad compression ignition engines with power $>560 \mathrm{~kW}$ [23]). For the diesel engine, the operating point at higher $\mathrm{NO}_{\mathrm{x}}$ emission level was selected, as engine operation at the engine-out $\mathrm{NO}_{\mathrm{x}}$ emission level of the gas engine is not possible without EGR with the diesel concept.

It can be seen that the highest efficiency was achieved with the monofuel gas engine despite its low $\mathrm{NO}_{\mathrm{x}}$ target. The advantage of the concept is its possible early combustion phasing as a result of premixed combustion at high EAR. The gas scavenged prechamber provides sufficient ignition of the very lean homogeneous mixture. Although not only the compression ratio but also the $\mathrm{NO}_{\mathrm{x}}$ target of the monofuel diesel engine are significantly higher, efficiency drops by $2 \%$ points compared to the gas concept. The mixing controlled combustion of the diesel engine, which is responsible for intensive $\mathrm{NO}_{\mathrm{x}}$ formation (cf., Refs. [24,25]), requires considerably retarded combustion phasing even though EAR is in the same range.

At the same MFB50\%, the efficiency of the dual fuel concept is lower than those of the monofuel concepts. By advancing combustion phasing, the efficiency of the gas engine can almost be achieved in dual fuel operation with 5\% diesel fraction. Reducing the diesel fraction to $0.5-1 \%$ limits the potential to advance MFB50\% (this effect is discussed in detail in the Detailed Analysis of Combustion Effects in Dual Fuel Operation With Small Diesel Fractions section). Hence, the maximum achieved efficiency is clearly below that of the gas engine.

For an accurate comparison, it is essential to take into account $\mathrm{NO}_{\mathrm{x}}$ emissions in dual fuel operation as well. Figure 2 shows the same operating points as Fig. 1, but in this case, the shading represents the $\mathrm{NO}_{\mathrm{x}}$ emission level within a range of $1-13 \mathrm{~g} / \mathrm{kWh}$. Although the main part of the dual fuel combustion process is pre-mixed combustion of the homogeneous gas-air mixture, $\mathrm{NO}_{\mathrm{x}}$ emissions are a magnitude greater than those of the gas engine point at the same combustion phasing. One reason for this is the reduced EAR of the dual fuel points. Because ignition of the homogeneous gas-air mixture with the injected pilot fuel is comparatively weak, the EAR level of the gas engine cannot be obtained. Furthermore, the nearly stoichiometric combustion of the small injected diesel amount significantly contributes to overall $\mathrm{NO}_{\mathrm{x}}$ emissions [26].

\footnotetext{
${ }^{3}$ The efficiency of the ideal engine is calculated based on a constant volume combustion process under consideration of the real charge.
} 
Compared to the diesel concept, the dual fuel concept seems to be more promising. When operated with very small diesel fractions, lower $\mathrm{NO}_{\mathrm{x}}$ emissions are possible at the same level of efficiency. However, it should be noted that combustion stability at such diesel fractions is significantly worse than that of the diesel engine.

In the discussion of Figs. 1 and 2, differences in efficiency between dual fuel, gas and diesel engine concepts were primarily explained by the influence of combustion phasing and excess air ratio. More detailed insight into the differences between the engine concepts is provided by a loss analysis according to Pischinger et al. [17]. The objective of this analysis is to compare the dual fuel concept with the monofuel concepts presented in Figs. 1 and 2 at the $\mathrm{NO}_{\mathrm{x}}$ level of the gas engine. A very low diesel fraction is required to achieve this level with the dual fuel concept, hence an appropriate operating point was measured at a diesel fraction of $0.75 \%$ with the wide range injector.

Figure 3 illustrates the results of the loss analyses of the three engine concepts. The differences in the indicated high pressure efficiencies ( $\mathrm{g}_{\mathrm{I} \text { HP }}$ ) arise from the differences in the efficiency of the ideal engine $\left(\mathrm{g}_{\mathrm{IE}}\right)^{3}$ as well as the differences in losses from imperfect combustion $\left(\mathrm{Dg}_{\mathrm{IC}}\right),{ }^{4}$ real combustion $\left(\mathrm{Dg}_{\mathrm{RC}}\right),{ }^{5}$ and heat transfer $\left(\mathrm{Dg}_{\mathrm{HT}}\right){ }^{6}$ In addition, Fig. 4 presents the heat release rate (HRR) curves that correspond to the operating points from Fig. 3.

Figure 3 reveals that the gas engine starts at a higher level of $g_{I E}$ than the dual fuel concept due to the higher EAR and marginally higher compression ratio. The gas engine has significant losses from imperfect combustion, which are nevertheless slightly smaller than with the dual fuel engine. With its early combustion phasing and its compact combustion shape, it has a clear advantage in losses from real combustion. Even though the losses from heat transfer caused by earlier combustion phasing and a higher compression ratio are larger than with the dual fuel engine, the gas engine has smaller losses overall and is thus able to achieve significantly higher indicated high pressure efficiency.

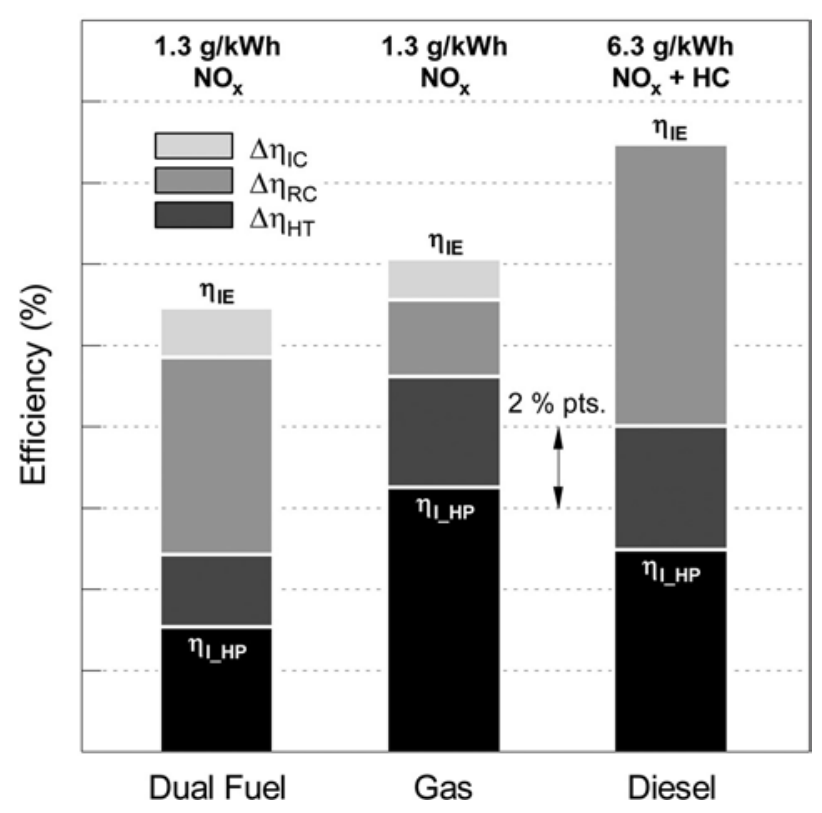

Fig. 3 Loss analysis-comparison of monofuel engine concepts and the dual fuel concept

With its high compression ratio, the diesel engine has a substantial advantage in terms of ideal engine efficiency. Low emissions of unburned species lead to significantly fewer losses from imperfect combustion than with the dual fuel engine; however, the late combustion phasing, which is clearly visible in Fig. 4, causes greater

\footnotetext{
${ }^{4}$ Losses from imperfect combustion are due to fuel species which leave the engine unburned or partly burned.

${ }^{5}$ Losses from real combustion are due to the deviation of the real combustion process from the constant volume combustion process of the ideal engine.

${ }^{6}$ Losses from heat transfer are due to heat transfer from the combustion gas to the combustion chamber walls.
} 
losses from real combustion. Losses from heat transfer are also greater than with the dual fuel concept mainly because of the comparatively high compression ratio. Overall, the diesel engine has greater losses than the dual fuel engine but still yields an advantage in g__HP $_{\text {due to its high gIE }}$ starting point.

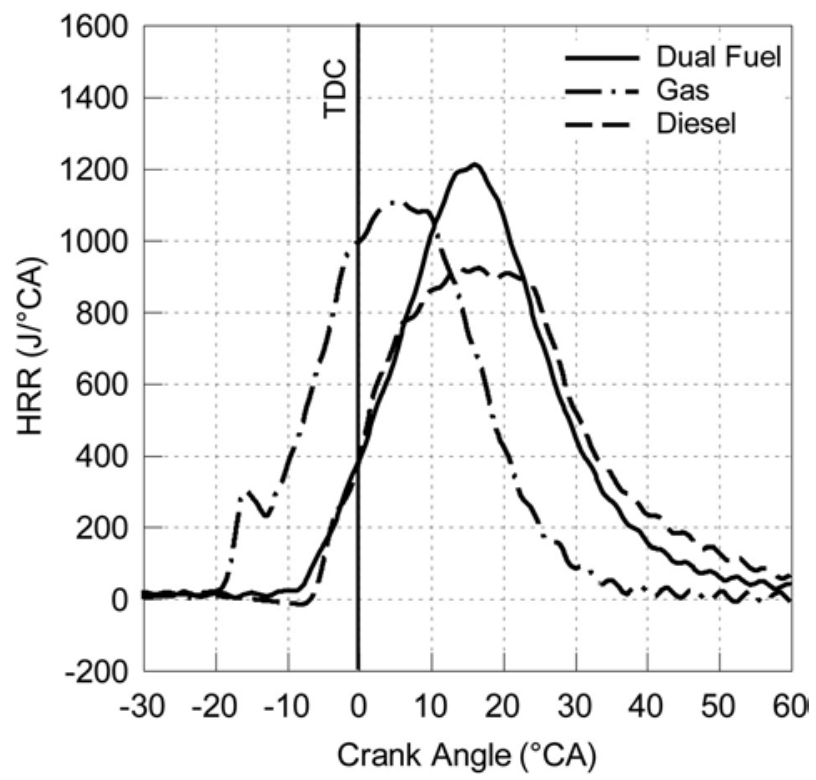

Fig. 4 Heat release rate curves-comparison of monofuel engine concepts and the dual fuel concept

It should be noted that late combustion phasing is required with the dual fuel operating point to achieve the low $\mathrm{NO}_{\mathrm{x}}$ level with a comparatively low EAR of 1.7 necessary to maintain reasonable combustion stability. Nevertheless, the coefficient of variation of IMEP is $1.5 \%$ points higher than with the gas engine and $1.9 \%$ points higher than with the diesel engine.

The results presented in this section demonstrate that certain limiting factors exist that prevent the dual fuel engine from performing as well as the gas engine. With the small diesel fractions required to achieve a comparably low $\mathrm{NO}_{\mathrm{x}}$ level, the early combustion phasing and high excess air ratio of the gas engine are not possible. This is due to the weaker ignition performance of the small injected pilot fuel amount compared to that of the gas scavenged prechamber of the gas engine. With the dual fuel engine, this results in a penalty in $g_{\text {I_HP }}$ of $3.5 \%$ pts.

On the other hand, the dual fuel concept has the potential to compete with the diesel engine since the same efficiency can be achieved at a $\mathrm{NO}_{\mathrm{x}}$ level of $3.5 \mathrm{~g} / \mathrm{kWh}$, which is lower than the $6.3 \mathrm{~g} / \mathrm{kWh}$ of the diesel engine. However, future development must focus on improving the combustion stability of dual fuel operation at small diesel fractions.

The ignition process of the gas mixture plays a leading role in combustion stability. Better understanding of what affects this process would enable the combustion process to be optimized so that the performance of the dual fuel engine approaches that of the gas engine. As a result, detailed research was carried out at LEC GmbH and CMT-Motores Termicos; this work will be presented in the Detailed Analysis of Combustion Effects in Dual Fuel Operation With Small Diesel Fractions section.

\section{Detailed Analysis of Combustion Effects in Dual Fuel Operation With Small Diesel Fractions}

In Figs. 1 and 2, it was shown that low $\mathrm{NO}_{\mathrm{x}}$ emissions require diesel fractions in the range of 1\%; however, advancing combustion phasing and increasing EAR in order to improve efficiency are issues with such a small diesel amount. Therefore, it was investigated how the combustion process is affected when the diesel fraction is lowered from $3 \%$ to $1 \%$ at full load operation. The interpretation of the SCE results is supported by optical spray 
box investigations, injection rate measurements, and 3D CFD simulation. All results discussed in this section are based on the wide range injector.

Figure 5 shows selected SCE results of injection timing variations with diesel fractions of 1\%, 1.5\%, and 3\% at IMEP 24bar and at a rail pressure of 1600bar. All other boundary conditions and engine settings were kept constant.

Advancing combustion phasing by advancing injection timing at 3\% diesel fraction is limited due to knocking combustion. Since the operating point at the knocking limit has the earliest combustion phasing and the highest efficiency, it serves as the reference when the other diesel fractions are compared with regard to indicated high pressure efficiency. When the diesel fraction is less than or equal to $1.5 \%$, knocking is not a limiting factor. However, the results show that with decreasing diesel fraction, the earliest possible combustion phasing shifts to later crank angles. Further advancement of injection timing based on the operating point with the earliest possible MFB50\% results in the retarding of combustion phasing. This fundamental effect has already been described in the literature but those investigations were based on different engine boundary conditions than the investigations in this paper, cf., Refs. [3,5,11,15].

Comparing 3\% and 1\% diesel fraction, it can be seen that there is a difference of 8CA in terms of earliest MFB50\%. As a consequence, the indicated high pressure efficiency drops significantly with the smaller diesel fraction, but also the $\mathrm{NO}_{\mathrm{x}}$ emission level is considerably lower. To minimize $\mathrm{NO}_{\mathrm{x}}$ emissions, it is preferable to select injection timings earlier than the injection timing of the operating point with the earliest combustion phasing. This approach is also beneficial with regard to efficiency. 


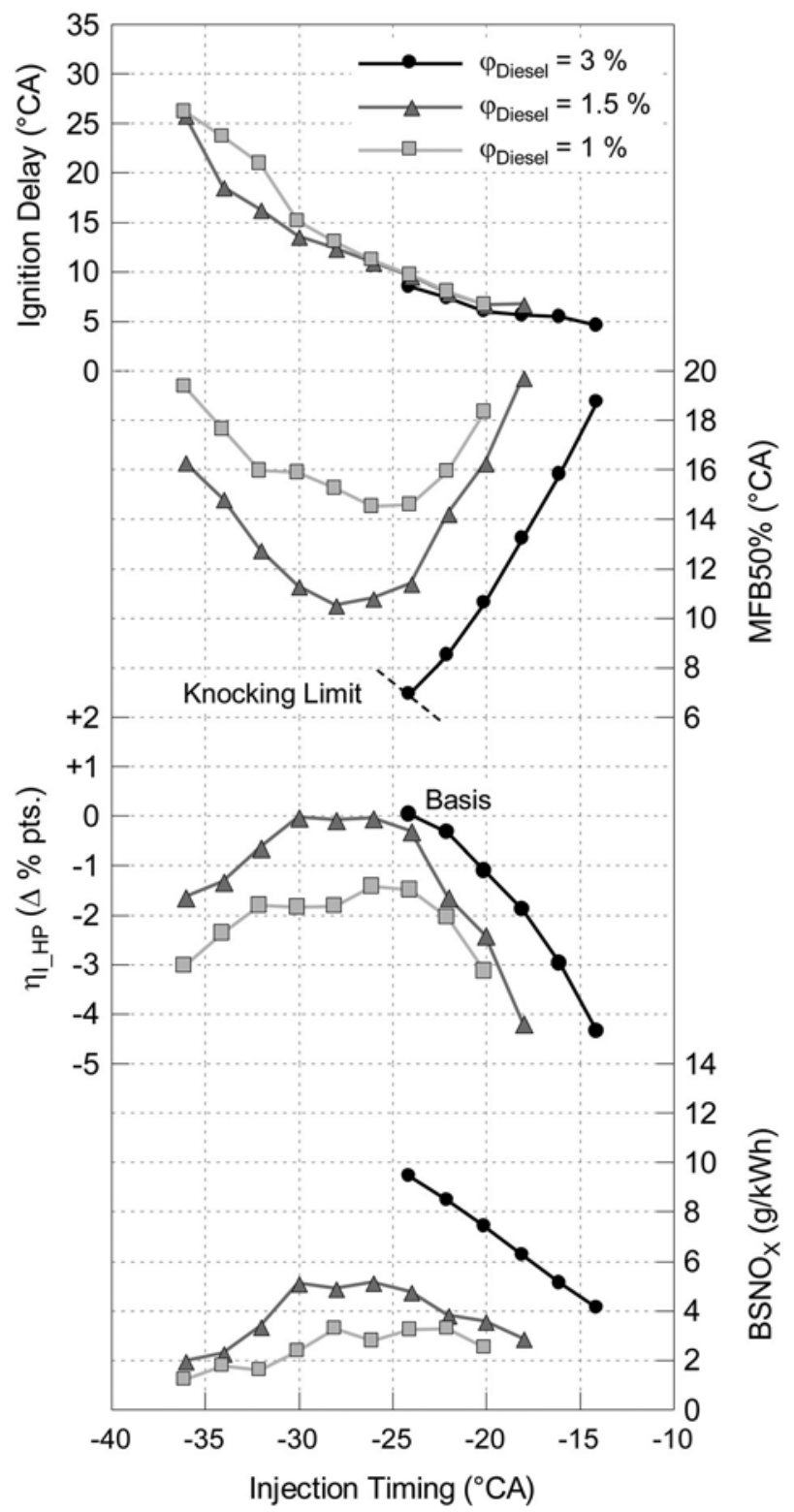

Fig. 5 Influence of diesel fraction reduction on the combustion process

It can be assumed that combustion behavior with the smallest investigated diesel fractions is mainly influenced by the ignition delay of the diesel fuel depicted at the top of the diagram. Ignition delay is defined as the duration between start of injection and start of combustion (defined as $1 \%$ of the maximum heat release rate). For all operating points shown, injection is completed before the diesel ignites. However, there is a difference of more than 20CA in ignition delay between the latest and the earliest injection timings. Since ignition delay depends strongly on temperature (cf., Ref. [17]), these very long durations are caused by a comparatively low temperature level in the combustion chamber at the end of the compression stroke which comes with the low compression ratio of the dual fuel engine, cf., Ref. [27]. In addition, the methane content of the gas-air mixture has a significant influence on the ignition delay [28]. By advancing injection timing, it can be expected that the longer ignition delay enables deeper penetration of the injected diesel fuel into the combustion chamber and better mixing with the homogenous gas-air mixture, cf., Refs. [26,28]. It is probable that this considerably influences the area of self-ignition and hence the development of the initial flame front surface. 
Based on selected measurement points from Fig. 5, a deeper insight is given into the effects of diesel fraction reduction and injection timing variation on the combustion process.

Influence of Diesel Fraction Reduction on the Combustion Process. Figure 6 shows the heat release rate curves and the corresponding ROI curves of the three operating points with 3\%, 1.5\%, and 1\% diesel fraction, all of which have the same injection timing as the operating point at the knocking limit in Fig. 5 . As the ROI curves indicate, the injector was operated in the ballistic area, which means that the needle did not fully open.

All HRR curves have approximately the same start of combustion, but during the first combustion phase, the HRR increases faster with higher diesel fraction due to a more distinct premixed diesel combustion peak, cf., Ref. [24]. Because of more intensive ignition of the homogeneous gas-air mixture, the main combustion process is also faster. Therefore, the HRR with $3 \%$ diesel fraction has the earliest combustion phasing and the HRR with $1 \%$ diesel fraction the latest. The oscillations in the heat release rates are caused by the premixed diesel combustion and are referred to as ringing [29]. It should be noted that the piezoelectric pressure transducer was nearly flush-mounted in the cylinder head (3.5 mm distance from the pressure transducer to the fire deck).

To obtain greater understanding of the effects of pilot injection on combustion behavior, the pilot spray was optically investigated in a spray box. The crank angle area investigated is indicated in gray in Fig. 6 and ranges from the start of injection to just before the start of combustion. As described in the section on the experimental setup, two optical methods were used: Mie scattering technique for the liquid spray phase and Schlieren technique for the vapor phase. Figure 7 shows two injection events with diesel masses corresponding to engine operation at $3 \%$ and $1 \%$ diesel fraction.

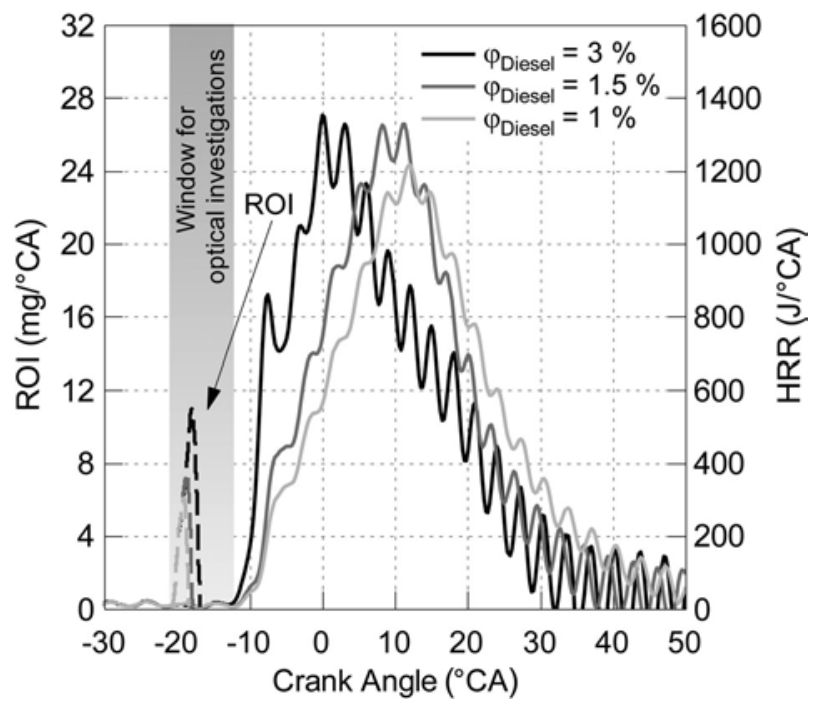

Fig. 6 ROI curves and heat release rate curves of different diesel fractions at constant injection timing

The images with a black background illustrate the liquid phase and the images with a white background the vapor phase. Each picture corresponds to one time-step in the spray penetration diagram; the dotted and dashed line indicates the liquid penetration of the spray and the solid line shows the vapor penetration. The time steps are calculated from the start of energizing of the injector. The penetration length of both the liquid spray and the vapor spray at each crank angle was determined from the spray images and averaged over all nozzle holes and over 20 injection events. 

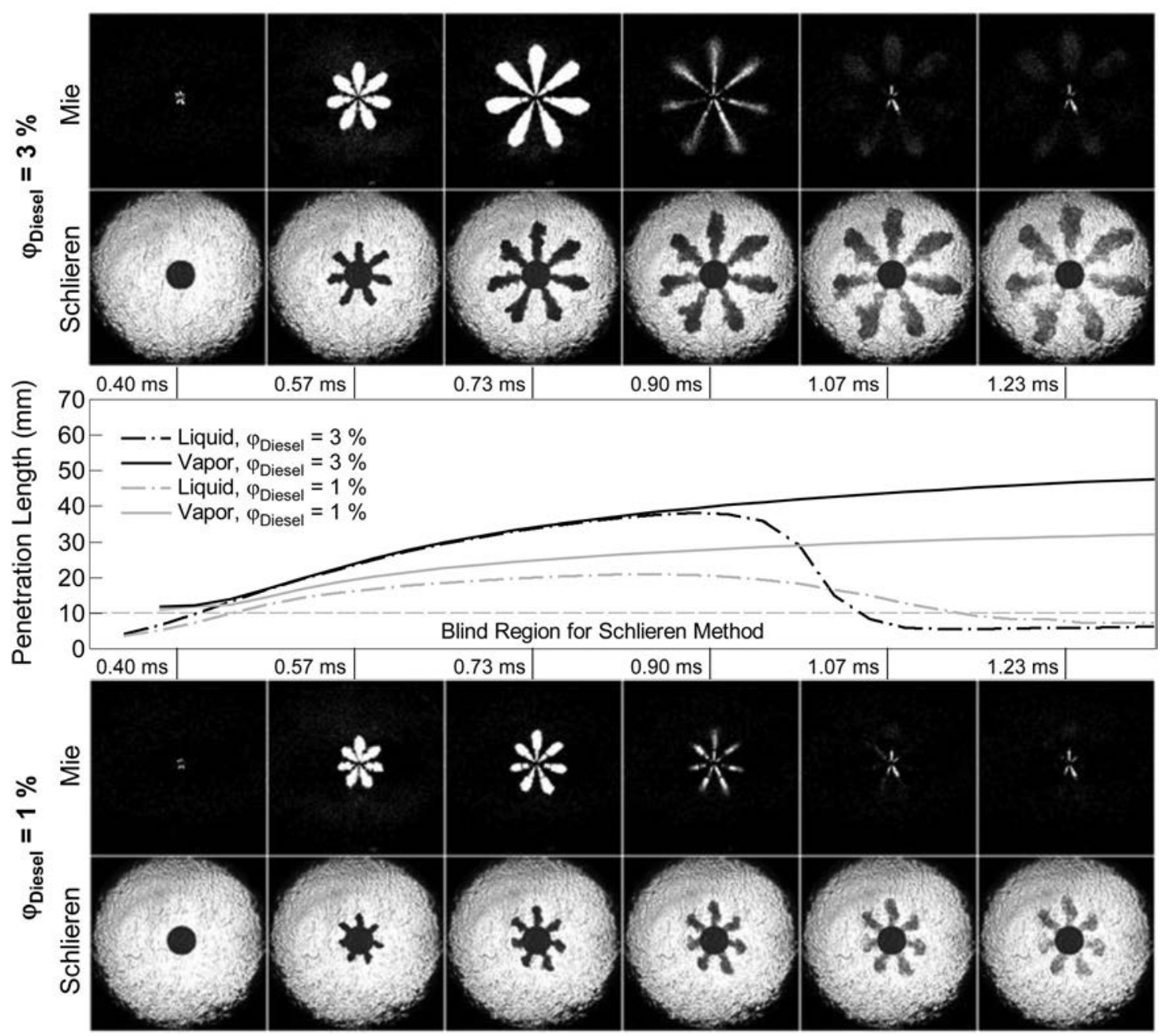

Fig. 7 Spray visualization and spray penetration length for diesel fractions of 1 and $3 \%$

The Schlieren technique requires the placement of a mirror behind the injector nozzle, thereby creating an area where the spray is not visible, cf., Ref. [10]. This "blind" area has a radius of $10 \mathrm{~mm}$ which is indicated in the diagram with a broken line. In the Schlieren images, the blind area is the black circle in the middle of the pictures.

At the first time-step of the sequence (start of injection), it can be seen that the spray in the liquid phase penetrates slightly. No spray is visible in the Schlieren images because the penetration length of the spray does not extend beyond the blind area. At the second and third time-steps, the spray plumes in the liquid phase and the vapor phase increase and extend beyond the blind area. With both diesel fractions, slight spray-to-spray scattering of the penetration length can be observed.

From time-step 4 on, the injector needle is closed. The liquid phase starts to disappear as the diesel fuel vaporizes. However, a very short penetration of the liquid phase-likely caused by injector dribble — can still be observed at this stage. Therefore, it should be considered that the determined penetration length of the liquid phase must be interpreted with caution after the end of the main injection event. Differences in dribble behavior depending on the diesel fraction may explain the differences in the falling sections of the curves. The vaporized spray plumes continue to radiate outward to the edges of the optical access; however, the penetration speed decreases considerably. In the last Schlieren pictures (just before the start of combustion), highly vaporized spray plumes that move away from the injector nozzle are visible.

The penetration length in the liquid phase and in the vapor phase is much longer with 3\% diesel fraction than with $1 \%$ diesel fraction. It can be assumed that the faster combustion process with higher diesel fractions is linked 
not only to the higher energy content of the ignition source but also to the longer penetration length. It is probable that deeper spray penetration into the combustion chamber increases the initial flame front surface, which causes faster combustion of the gas-air mixture, especially at the start of combustion. A greater injected diesel mass may also lead to a higher turbulence level in the combustion chamber, and therefore, to a higher turbulent flame speed. However, this topic was not investigated in depth in this paper.

At the selected engine operating points, reducing the diesel fraction from 3 to $1 \%$ causes a drop in g__HP of $1.5 \%$ pts. To improve the efficiency and stability of the dual fuel combustion process with diesel fractions of $1 \%$, attention must be paid to optimizing the spray penetration of the pilot spray. The observed asymmetry of the spray plumes might also have an impact on the heat release rate and on combustion stability. This effect is currently the subject of detailed investigations. Especially for diesel-gas combustion concepts with only one wide range injector for engine operation in pure diesel mode and in gas mode, the emphasis must be placed on enhancing nozzle geometry to prepare the spray sufficiently.

Influence of Varying Start of Injection on the Combustion Process. To investigate the phenomenon of reversal of combustion phasing when injection timing is varied at very small diesel fractions (cf., Fig. 5), three representative operating points with $1.5 \%$ diesel fraction were chosen for detailed analysis. These include the operating point with the earliest achievable MFB50\% as well as the two operating points with a MFB50\% of 16CA after TDC. The corresponding ROI curves and HRR curves are presented in Fig. 8. The operating points are referred to as injection timing early, medium, and late depending on their timing. The diagram illustrates that at late injection timing, a distinct premixed combustion peak is visible which is likely caused by combustion of the diesel pilot fuel. Further combustion is comparatively slow and delayed. At the medium injection timing, start of combustion happens at a crank angle similar to the late timing, but faster combustion and a higher maximum heat release rate cause earlier combustion phasing. A premixed diesel combustion peak is faintly visible. At the early injection timing, combustion is comparatively fast and has a high maximum HRR, but phasing is retarded due to the comparatively late start of combustion. The first main rise in the HRR curve clearly develops later than at the other injection timings. In addition, the HRR curve does not contain any visible premixed diesel combustion peak. It should be noted that a small peak is visible before the start of combustion. It possibly arises from a "cool flame" of diesel pilot fuel, similar to the first stage of a heat release rate curve typical for homogeneous charge compression ignition combustion, cf., Ref. [30]; however, this effect has to be investigated in more detail.

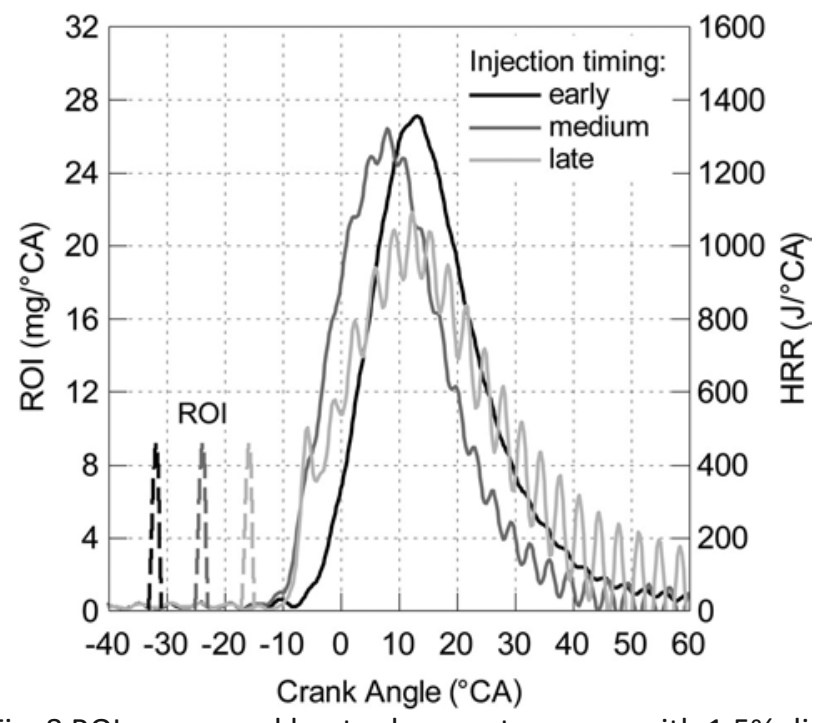

Fig. 8 ROI curves and heat release rate curves with $1.5 \%$ diesel fraction at different injection timings 


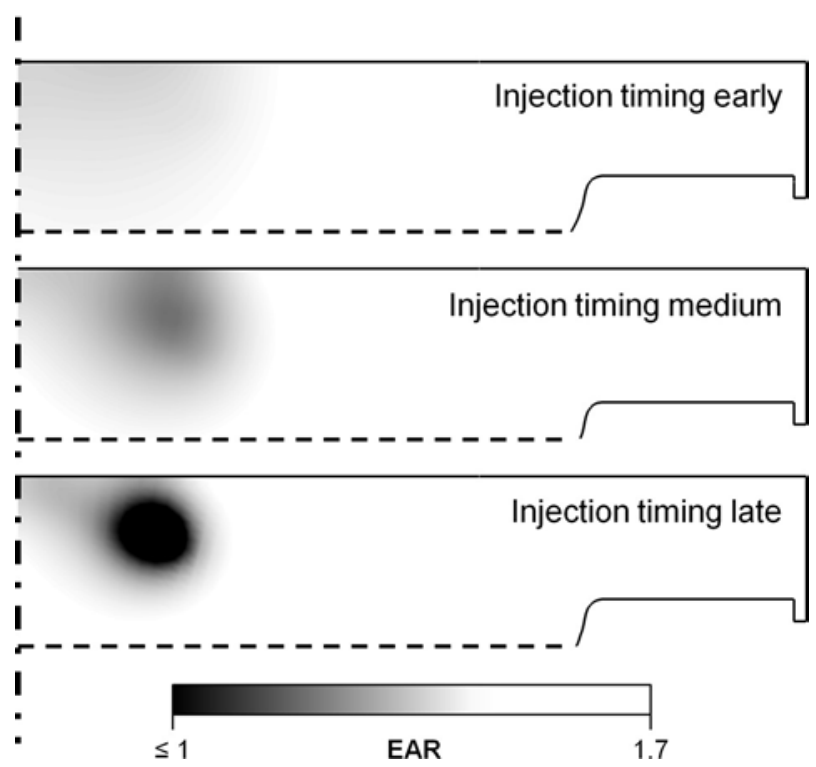

Fig. 9 Simulated local excess air ratio at the start of combustion with early, medium, and late injection timings

To obtain a better understanding of the different combustion behavior of the three injection timings, the mixture formation was investigated using 3D CFD simulation with the commercially available CFD code AVL FIRE. The simulation of each of the measurement points consists of the high pressure phase and starts at IVC and ends at the start of combustion. From the results of the analysis of the experimentally determined pressure traces (carried out with the software LEC CORA, which uses crank angle and timebased measurement data as an input), the initial conditions in the combustion chamber at IVC were defined (e.g., pressure, temperature, and gas composition). Turbulence was modeled with the standard k-zeta-f model [31]. Since the injector nozzle holes are arranged symmetrically, a sector mesh with radially aligned hexahedral cells was used to model the geometry of the combustion chamber. The mesh consisted of 121,000 cells at BDC and 25,000 cells at TDC. Spray breakup and evaporation were modeled with Kelvin-Helmholtz-Rayleigh-Taylor and Dukowicz models, respectively [32]. The measured injection rate was used as simulation input.

Figure 9 provides simulation results from the investigated injection timings. Local EAR values are plotted along a cross section from the cylinder axis (broken-dotted line, left side) to the liner (right side). The axis of the diesel spray is located on the cross section. Each plot is bordered by the fire deck at the top and by the piston at the bottom. As indicated by the dashed lines, the complete piston geometry is not shown.

At each injection timing, the EAR plot is presented at 0.5CA before the start of combustion. It can be seen that at the early timing with its long ignition delay, the injected diesel mass is subject to pronounced homogenization. At the start of combustion, the mixture in the area close to the cylinder axis is only slightly richer than the lean background gas-air mixture. Despite the early injection timing, it appears that not only the low in-cylinder temperature at the start of injection but also the homogenization of the diesel fuel with the background mixture cause the comparatively late start of combustion. This theory is supported by the fundamental studies of Ciezki and Adomeit [33] and Pfahl et al. [34], which have revealed that the ignition delay of diesel-air mixtures increases with increasing EAR. The widely diffused diesel vapor is likely responsible for a large initial flame front surface at the start of combustion, which results in fast main combustion.

In contrast, mixture formation at the late injection timing leads to a comparatively rich and compact cloud at the start of combustion. The distinct premixed peak that comes with this operating point may be explained by investigations of Dec [24], who found that the sudden premixed combustion of the diesel fuel takes place at a low local EAR.

At the medium timing, it appears that the mixture is still rich enough to allow for an early start of combustion but also consists of a cloud which diffuses widely enough to provide a large initial flame front surface, thereby causing comparatively fast gas combustion. 
In Fig. 5, it can be observed that while the early and the late injection timings exhibit very similar combustion phasing, the early timing is generally favorable since it is more advantageous than the late injection timing in terms of both efficiency ( $0.8 \%$ pts.) and $\mathrm{NO}_{\mathrm{x}}$ emissions $(1.6 \mathrm{~g} / \mathrm{kWh})$. These advantages are due to the beneficial shape of the heat release rate curve and the virtually nonexistent diesel premixed combustion peak, respectively.

\section{Summary and Outlook}

Interest is growing in using fully flexible diesel-gas dual fuel engines that are able to run in pure diesel mode as well as in dual fuel mode for various applications. This paper compared the performance of a state-of-the-art diesel-gas dual fuel concept to the performances of a monofuel gas engine and a monofuel diesel engine, evaluating its potential and limitations at very small diesel fractions.

The results of single cylinder engine measurements revealed that certain limiting factors exist that prevent the dual fuel engine from performing as well as the superior gas engine. With the small diesel fractions required to achieve the low $\mathrm{NO}_{\mathrm{x}}$ level of $1.3 \mathrm{~g} / \mathrm{kWh}$, the early combustion phasing and high excess air ratio of the gas engine are not possible, thereby leading to a penalty in $\mathrm{g}_{\text {I_HP }}$ of $3.5 \%$ pts. This behavior can be attributed to the ignition performance of the injected pilot fuel which is weaker than that of the gas scavenged prechamber in the gas engine. On the other hand, the dual fuel concept has the potential to compete with the diesel engine as the same efficiency can be achieved at a $\mathrm{NO}_{\mathrm{x}}$ level of $3.5 \mathrm{~g} / \mathrm{kWh}$, which is lower than $6.3 \mathrm{~g} / \mathrm{kWh}$ of the diesel engine.

To further optimize the dual fuel concept, especially in terms of combustion stability at small diesel fractions, it is necessary to understand the fundamental effects that influence the ignition process of the gas mixture by the diesel pilot fuel. To this end, combustion effects were analyzed in detail with optical investigations in a spray box, measurements of injection rates, and 3D CFD simulation to obtain greater insight into this process. The results suggest that diesel pilot injection and preparation of the spray play a leading role in influencing the combustion process.

Findings from the spray box investigations indicate that deeper spray penetration is beneficial for fast combustion of the gas-air background mixture. Reducing the diesel fraction from 3\% to $1 \%$ leads to a $30 \%$ shorter vapor spray penetration at the start of combustion for the analyzed engine operating points, which, in combination with the lower ignition energy of the reduced diesel mass, causes slower combustion and a drop in g__HP of $1.5 \%$ pts. Thus, focus must be placed on optimizing the pilot spray at very small injected diesel amounts to improve engine efficiency and combustion stability.

With regard to injection timing at very small diesel fractions $1.5 \%$, it was found that varying the timing leads to significantly different combustion characteristics. Three-dimensional CFD simulation revealed that the conditions at the start of combustion can range from pronounced homogenization of the diesel and the gas-air mixture to a comparatively rich and compact diesel cloud depending on differences in ignition delay. Early injection timings with good homogenization of the mixture are preferable for low $\mathrm{NO}_{\mathrm{x}}$ emissions, as better efficiencies can be achieved with these injection timings than with late injection timings at the same $\mathrm{NO}_{\mathrm{x}}$ emission level. For example, the comparison of two selected operating points with the same MFB50\% but with different injection timings showed a $0.8 \%$ pts higher $\mathrm{g}_{\_} \mathrm{HP}$ and $1.6 \mathrm{~g} / \mathrm{kWh}$ lower $\mathrm{NO}_{\mathrm{x}}$ emissions at the early injection timing. Since early injections of the pilot fuel go hand in hand with very long ignition delays, however, further investigation is required to determine how well they can be applied to a series engine.

\section{Acknowledgment}

The authors would like to acknowledge the financial support of the "COMET-Competence Centres for Excellent Technologies Programme” of the Austrian Federal Ministry for Transport, Innovation and Technology (BMVIT); the Austrian Federal Ministry of Science, Research and Economy (BMWFW); and the Provinces of Styria, Tyrol, and Vienna for the K1-Centre LEC EvoLET. The COMET Programme is managed by the Austrian Research Promotion Agency (FFG).

\section{Funding Data}

Austrian Research Promotion Agency (FFG) (844604). 


\section{Nomenclature}

BDC bottom dead center

CA crank angle

CFD computational fluid dynamics

EAR excess air ratio

EGR exhaust gas recirculation

FSO full scale output

HC nonmethane hydrocarbons

HRR heat release rate

IMEP indicated mean effective pressure

IVC intake valve closing

MFB50\% mass fraction burned 50\%

$\mathrm{NO}_{\mathrm{x}}$ nitrogen oxides

ROI rate of injection

SCE single cylinder engine

TDC top dead center

$\mathrm{Dg}_{\mathrm{HT}}$ losses from heat transfer

Dg IC losses from imperfect combustion

$\mathrm{Dg}_{\mathrm{RC}}$ losses from real combustion

$\mathrm{g}_{\mathrm{IE}}$ efficiency of the ideal engine

gI_HP indicated high pressure efficiency

\section{References}

[1] Mooser, D., 2007, “Brenngase und Gasmotoren,” Handbuch Dieselmotoren, 3rd ed., K. Mollenhauer and H. Tsch€oke, eds., Springer, Berlin, p. 132ff.

[2] Buchholz, B., 2014, “Saubere Großmotoren f€ur die Zukunft-Herausforderung f€ur die Forschung,” Die Zukunft der Großmotoren III, 3. Rostocker Großmotorentagung, H. Harndorf, ed., FVTR Forschungszentrum f€ur Verbrennungsmotoren und Thermodynamik Rostock GmbH, Rostock, Germany, pp. 1-14.

[3] Krishnan, S. R., Srinivasan, K. K., Singh, S., Bell, S. R., Midkiff, K. C., Gong, W., Fiveland, S. B., and Willi, M., 2004, “Strategies for Reduced NOx Emissions in Pilot-Ignited Natural Gas Engines,” ASME J. Eng. Gas Turbines Power, 126(3), pp. 665-671.

[4] Mohr, H., and Frobenius, M., 2014, “Optimierung von Diesel-/Gas-Großmotoren f€ur unterschiedlichste Anwendungen,” Die Zukunft der Großmotoren III, 3. Rostocker Großmotorentagung, H. Harndorf, ed., FVTR Forschungszentrum f€ur Verbrennungsmotoren und Thermodynamik Rostock GmbH, Rostock, Germany, pp. 138-149.

[5] Raihan, M. S., Guerry, E. S., Dwivedi, U., and Srinivasan, K. K., 2015, "Experimental Analysis of Diesel-Ignited Methane Dual-Fuel LowTemperature Combustion in a Single-Cylinder Diesel Engine,” ASCE J. Energy Eng., 141(2), pp. $12-71$.

[6] Sell, J., 2015, “Marine Klassifikation Von Gasmotoren-Beweggr€unde, Anforderungen, Herausforderungen,” Ninth Dessau Gas Engine Conference, Dessau, Germany, Apr. 16-17, pp. 13-20.

[7] Troberg, M., Portin, K., and Jarvi, A., 2013, “Update on W€artsil€a 4 Stroke Gas Product Development,” CIMAC Congress, Shanghai, China, May 13-16, Paper No. 406.

[8] Watanabe, K., Goto, S., and Hashimoto, T., 2013, “Advanced Development of Medium Speed Gas Engine Targeting to Marine and Land,” CIMAC Congress, Shanghai, China, May 13-16, Paper No. 99.

[9] Redtenbacher, C., Kiesling, C., Wimmer, A., Sprenger, F., Fasching, P., and Eichlseder, H., 2016, "Dual Fuel Brennverfahren—Ein zukunftsweisendes Konzept vom PKW- bis zum Großmotorenbereich?,” 37 Internationales Wiener Motorensymposium, Apr. 28-29. Band 2: Zweiter Tag, D€usseldorf, Germany, H. P. Lenz, ed., pp. 403-428.

[10] Kiesling, C., Redtenbacher, C., Kirsten, M., Wimmer, A., Imhof, D., Berger, I., and Garcia-Oliver, J., 2016, “Detailed Assessment of an Advanced Wide Range Diesel Injector for Dual Fuel Operation of Large Engines,” CIMAC Congress, Helsinki, Finland, June 610, Paper No. 78.

[11] Eichmeier, J., Wagner, U., and Spicher, U., 2012, “Controlling Gasoline Low Temperature Combustion by Diesel Micro Pilot Injection,” ASME J. Eng. Gas Turbines Power, 134(7), p. 072802.

[12] Nieman, D. E., Dempsey, A. B., and Reitz, R. D., 2012, “Heavy-Duty RCCI Operation Using Natural Gas and Diesel,” SAE Int. J. Engines, 5(2), pp. 270-285.

[13] Srinivasan, K. K., Krishnan, S. R., Singh, S., Midkiff, K. C., Bell, S. R., Gong, W., Fiveland, S. B., and Willi, M., 2006, “The Advanced Injection Low Pilot Ignited Natural Gas Engine: A Combustion Analysis,” ASME J. Eng. Gas Turbines Power, 128(1), pp. 213-218. 
[14] Srinivasan, K. K., Krishnan, S. R., and Qi, Y., 2014, “Cyclic Combustion Variations in Dual Fuel Partially Premixed Pilot-Ignited Natural Gas Engines,” ASME J. Energy Resour. Technol., 136(1), p. 012003.

[15] Tomita, E., Kawahara, N., Piao, Z., and Yamaguchi, R., 2002, "Effects of EGR and Early Injection of Diesel Fuel on Combustion Characteristics and Exhaust Emissions in a Methane Dual Fuel Engine,” SAE Paper No. 2002-01-2723.

[16] Krishnan, S. R., Biruduganti, M., Mo, Y., Bell, S. R., and Midkiff, K. C., 2002, "Performance and Heat Release Analysis of a PilotIgnited Natural Gas Engine,” Int. J. Engine Res., 3(3), pp. 171-184.

[17] Pischinger, R., Klell, M., and Sams, T., 2009, “Thermodynamik der Verbrennungskraftmaschine,” Der Fahrzeugantrieb (Technical Book Series), 3rd ed., H. List, ed., Springer, Vienna, Austria, pp. 102, 338f, 349ff.

[18] Pucher, H., 2007, "Ladungswechsel und Aufladung," Handbuch Dieselmotoren, 3rd ed., K. Mollenhauer and H. Tsch€oke, eds., Springer, Berlin, p. 59.

[19] Trapp, C., B€owing, R., and Tinschmann, G., 2015, “Off-Highway-Gasmotoren,” Erdgas und erneuerbares Methan fur den Fahrzeugantrieb€ , 1st ed., R. Van Basshuysen, ed., Springer Vieweg, Wiesbaden, Germany, p. 470.

[20] Laiminger, S., Trapp, C., Schaumberger, H., and Fouquet, M., 2011, “Die n€achste Generation von Jenbacher Gasmotoren von GEdie wegweisende Kombination von zweistufiger Aufladung und innovativen Brennverfahren,” Seventh Dessau Gas Engine Conference, Dessau, Germany, Mar. 24-25, pp. 39-48.

[21] Bosch, W., 1964, "Der Einspritzgesetz-Indikator, ein neues Meßger€at zur direkten Bestimmung des Einspritzgesetzes von Einzeleinspritzungen,” Motortech. Z., 25(7), pp. 268-282.

[22] Bundesministerium f€ur Umwelt, Naturschutz und Reaktorsicherheit, 2002, "Erste Allgemeine Verwaltungsvorschrift zum BundesImmissionsschutzgesetz (Technische Anleitung zur Reinhaltung der Luft-TA Luft) vom 24, Juli 2002,” Berlin, Germany, accessed Jan. 14, 2016, http://www.bmub.bund.de/fileadmin/Daten_BMU/Download_PDF/Luft/taluft.pdf

[23] United States Environmental Protection Agency, 2015, “Code of Federal Regulations, Title 40, Protection of Environment,” 40 CFR 89.112, Table 1, United States Environmental Protection Agency, Washington, DC, accessed Dec. 16, 2015, https://www.gpo.gov/fdsys/browse/collectionCfr. action?ccollection Cod CFR

[24] Dec, J., 1997, “A Conceptual Model of DI Diesel Combustion Based on LaserSheet Imaging,” SAE Paper No. 970873.

[25] Heywood, J., 1988, Internal Combustion Engine Fundamentals (Technical Book Series), McGraw-Hill Series in Mechanical Engineering, New York, J. Holman, ed., p. 586 ff. Vol. 140, MARCH 2018 Krenn, M., Redtenbacher, C., Pirker, G., and Wimmer, A., 2015, “A New Approach for Combustion Modeling of Large Dual-Fuel Engines,” Heavy-Duty-, on- und Off-Highway-Motoren, 10 Internationale MTZ-Fachtagung, Speyer, Germany, pp. 1-14.

[26] Krenn, M., Pirker, G., Wimmer, A., Djuranec, S., Meier, M. C., Waldenmaier, U., and Zhu, J., 2014, “Methodology for Analysis and Simulation of Dual Fuel Combustion in Large Engines,” THIESEL Conference on Thermo- and Fluid Dynamic Processes in Direct Injection Engines, Valencia, Spain, Sept. 9-12, pp. 1-19.

[27] Schlatter, S., Schneider, B., Wright, Y., and Boulouchos, K., 2012, "Experimental Study of Ignition and Combustion Characteristics of a Diesel Pilot Spray in a Lean Premixed Methane/Air Charge using a Rapid Compression Expansion Machine,” SAE Paper No. 2012-01-0825.

[28] Kirsten, M., Pirker, G., Redtenbacher, C., Wimmer, A., and Chmela, F., 2016, “Advanced Knock Detection for Diesel/Natural Gas Dual Fuel Engine Operation,” SAE Paper No. 2016-01-0785.

[29] Vandersickel, A., 2011, “Two Approaches to Auto-Ignition Modelling for HCCI Applications,” Doctoral thesis, ETH Zurich, Zurich, Germany, p. 20.

[30] AVL List GmbH, 2014, “Advanced Simulation Technologies Software Documentation, AVL FIRE v2014, CFD Solver,” AVL List GmbH, Graz, Austria.

[31] AVL List GmbH, 2014, “AVL FIRE Version 2014, Spray Module,” Document No. 08.0205.2014, AVL List GmbH, Graz, Austria, pp. 2-6ff, 2-34.

[32] Ciezki, H., and Adomeit, G., 1993, "Shock-Tube Investigations of Self-Ignition of n-Heptane-Air Mixtures Under Engine Relevant Conditions,” Combust. Flame, 93(4), pp. 421-433.

[33] Pfahl, U., Fieweger, K., and Adomeit, G., 1996, "Self-Ignition of Diesel-Relevant Hydrocarbon-Air Mixtures Under Engine Conditions," 26th Symposium (International) on Combustion/the Combustion Institute, Pittsburgh, PA, pp. 781-789. 